\title{
KHIPU, LLAUTU: UNA FAMILIA DE TEXTOS TEXTILES ${ }^{1}$
}

\author{
KHIPU, LLAUTU: A FAMILY OF TEXTILE TEXTS \\ Lydia Fossa*
}

\begin{abstract}
Los patrones estilísticos del arte textil de cada grupo étnico andino expresan información específica. Estos patrones pueden estar presentes en la elaboración del khipu, que es un textil. El khipu formaría parte de la familia textil de un grupo humano dado. La configuración estilística del khipu podría considerarse como señal identitaria de un grupo social dado, mi propuesta para el presente trabajo. La asociación de cada khipu arqueológico a un grupo étnico específico y, a su interior, a un nivel de administración indígena, es plausible.
\end{abstract}

Palabras clave: Khipu, llautu, grupo étnico, familia de textiles.

Textile art style patterns belonging to a unique ethnic group express specific information. They may be present in khipu configuration, since it is also a textile. Khipu would thus belong to the textile objects family of a given human group. Specific style khipu configuration could be considered an identity sign of a given ethnic group, which I propose in this article. The association of each archaeological khipu to a specific ethnic group and, within it, to a level of indigenous administration, is plausible.

Key words: Khipu, llautu, ethnic group, family of textiles.

\section{Introducción}

Desde el inicio de la investigación científica en las áreas de antropología, arqueología e historia andinas, los patrones estilísticos de la textilería y la cerámica han sido utilizados para establecer la pertenencia a un grupo étnico dado: textiles Paracas o Wari, cerámica Inka. Son parte de la identidad del grupo social que comparte territorio, arqueoarquitectura, lengua y costumbres. Cada característica confirma la otra, pues los diseños y su estilo aparecen en todas sus expresiones.

Una familia de textiles se establece a partir de su particular código de color, sus diseños y su patrón formal. Esta identidad se da por establecida y no se discutirá en el presente trabajo. En el khipu ${ }^{2}$ arqueológico, un objeto textil, esta estilística se puede observar en la estructura formal, colorido de la cuerda transversal y sus apéndices; en la confección, anclaje, torsión y distribución de las colgantes. La cuerda transversal rige el patrón de cuerdas colgantes (Fossa 2011), dándoles rasgos identitarios asociados a una expresión cultural específica.

La pregunta que surge aquí, como hipótesis, es: si los objetos textiles andinos exhiben una identidad étnica, cultural, ¿.podemos incluir en esa "familia" de textos textiles al khipu, que también es un objeto textil cargado de significado? Este significado se evidencia en la presencia del khipu en todos los grupos étnicos y niveles de la administración indígena.

Mi acercamiento a los khipu es a partir del análisis del discurso; considero que el khipu es un sistema de códigos que aún desconocemos ${ }^{3}$. La semántica histórica será útil para aclaraciones terminológicas sincrónicas bilingües, imprescindible cuando se trabaja con un corpus de fuentes en castellano del siglo XVI, pleno de préstamos indígenas. Abordaré los aspectos comunicativos de los khipu y llautu ${ }^{4}$ arqueológicos desde una perspectiva comparativa.

\section{Llautu}

En 1984, Carlos Radicati describía un grupo de textiles que compartían patrones de rasgos cromáticos, indicando que su estudio permitiría una mejor comprensión de los khipu:

“... el estudio de las rayas de colores y sus combinaciones en los llautus, mantos y camisetas de los incas y en las llicllas y chumpis de las coyas, claramente precisadas en muchas crónicas, podría constituir el primer paso en tal sentido [el desciframiento de los khipu] ..." (1984:380).

* Universidad ESAN, Lima, Perú. Correo electrónico: lfossa@ uesan.edu.pe 
Radicati se referiría a lo indicado por Pedro de Cieza de León, quien describe detalladamente el uso, forma y diseño de los llautu:

“... se usava en todo este reyno, lo primero, lo de las señales en las cabeças diferentes unas de otras, porque si eran yungas andavan arreboçados como jitanos, y si eran collas, tenian unos bonetes como hechura de morteros, hechos de lana, y si canas, tenian otros bonetones mayores y muy anchos; los cañares trayan unas coronas de palo delgado como aro de çedaço; los guancas unos ramales que les cayan por debaxo de la barba y los cavellos entrenchados; los chancas unas vendas anchas coloradas o negras por ensima de la frente; por manera que asi estos como todos los demas eran conoçidos por estas que tenian por ensinia, que era tan buena y clara que aunque oviera juntos quinientos mill honbres claramente se conoçieran los unos a los otros" (Cieza 1985 [ca1551]:68).

Esta cita es preciosa por la cantidad de información que nos brinda. Destaca la temprana información de la función identitaria del llautu que lucían los hombres, en la que insiste Cieza: "Los llautos y cordones que se ponen en las cabeças para ser conoçidos unos entre otros..." (Cieza 1985 [ca1551]:6).

Otro texto que leería Radicati sería el de Polo Ondegardo, gran conocedor de la cultura indígena "El tocado de los indios es todo diferente porque en ninguna provincia se usa lo que en otra..." (1990 [1571]:117). Se observa la exclusividad de cada patrón estilístico para cumplir con la funcionalidad identitaria. Es más específico: “... y en cada provincia tenian insignia para esto conforme al habito que traen, aunque lo general de manta y camiseta, son todavia en los tocados difieren y en otras cosas que se conoce de la provincia de cada uno, el que quisiere haber mirado en ello..." (1990 [1571]:120). Concuerda Sarmiento: "Inca Yupanqui, para conocer las naciones que había conquistado, mando que cada uno tuviese su vestido y tocado, a que llaman pillu o llaytu o chuco, diferente unos de otros, para que se diferenciasen y conociesen fácilmente" (1988 [1572]:119). Sarmiento llama "naciones" a lo que Ondegardo llama "provincias": se trataría de grupos de personas que habitan un territorio determinado, compartiendo rasgos culturales específicos.

Estas diferencias entre miembros de diferentes grupos humanos se pueden observar en los dibujos de Guamán Poma (1993 [1615?]), que grafican la indumentaria y los tocados de cada uno. Constituyen un catálogo donde corroborar la información que nos proporcionan las fuentes escritas. Ver Tabla 1.

Así como el llautu sirve de diferenciador masculino entre los múltiples grupos humanos que conviven en el área andina, la vinch ${ }^{5}$ desempeña similar papel para la población femenina. Sobre las vincha, dice Pachacuti Yamqui:

“... mandó que las hijas y moças de diez y seis años se peinaran sus cabellos, echando sus binchas, esto se llama [qui]cuchicui. ... Todo esto los abian hecho para que desde entonçes se llamaran y llamasen muger, como dezir tasque guarmi" (1993 [1613]:202).

Añade Pachacuti Yamqui que el propio Manco Capac mandó

“... que los bestidos y traxes [y binchas] de cada pueblo fuesen diferentes, como en hablar, para conoçer porque en este tiempo no echavan de ver y conosçer a los yndios qué nación o qué pueblo eran..." (1993 [1613]:198).

La variante más importante era el colorido y el diseño presente en los textiles, ya fueran llautu, vincha, mantellinas u otros. Si seguimos a Guamán Poma (1993 [ca1615]), observamos que el llautu, la manta y los objetos que lleva cualquier personaje indígena en las manos, así como el tipo de calzado, refuerzan la información acerca de la identidad del grupo étnico de la persona.

El cromatismo es uno de los aspectos más saltantes tanto en llautu como en khipu. Fue lo que más destacaron los autores en su momento y que sorprende hasta ahora (Tabla 1). Dentro de ese cromatismo está el patrón de colores: repeticiones, variaciones, combinatorias: "Pillaca llayto (llautu). Llaytu de dos colores, morado y negro, texidos en contra" (González 1989 [1608]:285). Primero menciona el colorido y luego resalta un factor adicional: la técnica empleada, de urdimbres complementarias. El hecho de estar "texidos en 
Tabla 1. Tipos de Llautu.

\begin{tabular}{|c|c|c|}
\hline Nombre & Descripción & Fuente \\
\hline [identificador] & $\begin{array}{l}\text { "Los llautos y cordones que se ponen en las cabeças para ser conoçidos unos } \\
\text { entre otros...". }\end{array}$ & $\begin{array}{l}\text { (Cieza [1553] } \\
\text { 1985: 6) }\end{array}$ \\
\hline pillaca & $\begin{array}{l}\text { “... el que avia de ser Ynga... y en la cabeça con una trença leonada se a de } \\
\text { dar çiertas bueltas...". }\end{array}$ & $\begin{array}{l}(\text { Cieza }[1553] \\
1985: 18)\end{array}$ \\
\hline & $\begin{array}{l}\text { “... en la cabeça se ponían unas trenças o llauto, que llaman 'pillaca'; ques } \\
\text { como corona, debaxo del qual colgavan unas orejeras de oro y ençima se ponía } \\
\text { un bonete de pluma casi como diadema que ellos llaman "paucarchuco"”. }\end{array}$ & $\begin{array}{l}(\text { Cieza }[1553] \\
1985: 18-19)\end{array}$ \\
\hline yungas & porque si eran yungas andavan arreboçados como jitanos, & $\begin{array}{c}(\text { Cieza }[1553] \\
1985: 68)\end{array}$ \\
\hline collas & y si eran collas, tenian unos bonetes como hechura de morteros, hechos de lana, & \\
\hline canas & y si canas, tenian otros bonetones mayores y muy anchos; & \\
\hline cañares & los cañares trayan unas coronas de palo delgado como aro de çedaço; & \\
\hline guancas & $\begin{array}{l}\text { los guancas unos ramales que les cayan por debaxo de la barba y los cavellos } \\
\text { entrenchados; }\end{array}$ & \\
\hline chancas & los chancas unas vendas anchas coloradas o negras por ensima de la frente... & \\
\hline traxe de las caveças & $\begin{array}{l}\text { las quales provincias heran pobladas y lo son de presente de diferentes na- } \\
\text { ciones y lenguas de gentes todas las quales naciones se diferenciavan en el } \\
\text { traxe de las caveças...". }\end{array}$ & $\begin{array}{l}\text { (De la Bandera [1557] } \\
\text { en Levillier 1925: 279) }\end{array}$ \\
\hline Llautu de Atahualpa & $\begin{array}{l}\text {... se ponía en la caveça unos llautos, que son unas trenças hechas de lana de } \\
\text { colores, de grosor de un medio dedo, y de anchor de uno ... hecho esto una } \\
\text { manera de corona, y no con puntas sino redonda, de anchor de una mano, } \\
\text { que encaxava en la caveça y en la frente una borla cosida en este llauto de } \\
\text { anchor de una mano poco más, de lana muy fina de grana, cortada muy ygual, } \\
\text { metida por unos cañutos de oro, muy subtilmente hasta la mitad; esta lana } \\
\text { hera hilada y de los cañutos para avajo destorida, que hera lo que caya en la } \\
\text { frente, que los cañutillos de oro hera quanto tomaban todo el llauto. cayale } \\
\text { esta borla hasta ençima de las cexas, de un dedo de grosor, que le tomaba } \\
\text { toda la frente. Todos estos señores andavan tresquilados y con los orexones } \\
\text { como a sobrepeine. }\end{array}$ & $\begin{array}{l}\text { (Pizarro 1986 } \\
{[\text { ca 1571]:66) }}\end{array}$ \\
\hline bonetillo de color & $\begin{array}{l}\text { "... avia yndios señalados para executar la justicia y que la señal que trayan } \\
\text { hera un cierto bonetillo de color en la caveça y trençados los cavellos...". }\end{array}$ & $\begin{array}{l}\text { (Levillier } 1925 \text { [1582]: } \\
\text { 285) }\end{array}$ \\
\hline corona de los reyes ingas & $\begin{array}{l}\text { la corona de los reyes ingas hera una borla que atava en la cabeça y esta no } \\
\text { la podia poner otra ninguna persona... }\end{array}$ & \\
\hline corona real & $\begin{array}{l}\text { En la cabeça traían un rodete redondo que ellos llaman llaitu, ancho de dos } \\
\text { dedos, el qual se ponían en la frente y en él chaquira, y otros dijes y piedras } \\
\text { preciosas, y allí asientan plumas y penachos (...) }\end{array}$ & $\begin{array}{l}\text { (Murúa en Perissat } \\
\text { 2000:634) }\end{array}$ \\
\hline Trenza-llautu del Inca & $\begin{array}{l}\text { Traían los Incas en la cabeza por tocado una trenza, que llaman llautu; } \\
\text { hacíanla de muchos colores y del ancho de un dedo y poco menos gruesa. } \\
\text { Esta trenza rodeaban a la cabeza, y daban cuatro o cinco vueltas, y quedaba } \\
\text { como una guirnalda. }\end{array}$ & $\begin{array}{l}\text { (Garcilaso en Perissat } \\
\text { 2000:634) }\end{array}$ \\
\hline Llautto & El llautto el ci[n]gulo que traen por sombrero. & $\begin{array}{l}\text { (González } 1989 \\
\text { [1608]:212, 285) }\end{array}$ \\
\hline Ppichuc & L(1)auto o faxa teñido de varios colores. & \\
\hline Pillaca llayto & Llaytu de dos colores, morado y negro, texidos en contra. & \\
\hline Pillaca llayto & Llauto de los yngas, texido de diversas colores. & $\begin{array}{c}\text { (Bertonio } 1879 \\
[1612]: 265) \\
\end{array}$ \\
\hline Capac $^{15}$ llaotto & Todos tres [Incas] bien bestidos, con sus capac llaottos y mascapacha & $\begin{array}{l}\text { (Pachacuti Yamqui } 1993 \\
\text { [1613]:233) }\end{array}$ \\
\hline
\end{tabular}

Fuente: Elaboración propia. 
contra" le añade significado a la pieza y la convierte en característica de un grupo específico.

Cada grupo étnico tenía un especial modo de peinarse y cortarse el cabello, aspectos que contribuían a que el llautu tuviera el rasgo único e identificatorio que buscaban. Pachacuti Yamqui detalla la costumbre general de darle forma a las cabezas de los niños: “... este mismo ynga [Manco Capac] los había mandado que ataran las cabeças de las criaturas..." (1993 [1613]:199). Además: "[Lluqui Yupanqui] los abia mandado que todas las naçiones a él sujetas los atasen las cabeças de las criaturas para que sean largos y quebrantados de frente..." (1993 [1613]:205). Así los llautu tendrían una mejor colocación y los rasgos identitarios serían más visibles:

\begin{abstract}
"Traían los Incas en la cabeza, por tocado, una trenza [que llaman llautu]. Hacíanla de muchos colores y del ancho de un dedo y poco menos gruesa. Esta trenza rodeaba a la cabeza y daba cuatro o cinco vueltas y quedaba como una guirnalda" (De la Vega 1995 [1609]:55).
\end{abstract}

Es tan recurrente la diferenciación étnica que Ondegardo se refiere no solo a la vestimenta, a la de sus khipu y llautu, sino también a otras expresiones culturales: “... hasta los bailes y cantares y manera de música si han mirado en ello... no lo dejarán, ni los unos usan lo de los otros" (1990:117). Cada grupo étnico tiene su propia especificidad, respeta la ajena y valora la propia. Es una diferenciación que confiere identidad, prestigio y sentido de pertenencia.

Resumiendo la información que nos ofrecen algunos de los autores de los siglos XVI y XVII, tenemos que el llautu o la vincha, complementado por la configuración craneana, el uso de orejeras y la manera de cortar y arreglar el cabello, es el principal, más inmediato, medio de transmitir identidad. Esta identidad indicaría, primero, la preeminencia, la etnia, el ayllu y, luego, el individuo. Las fuentes citadas solo nos dicen que se establecía la identidad étnica por medio del tocado y de las otras prendas, pero, como decía Ondegardo, "los que quisieren haber mirado en ello", se hubieran percatado, además de la identidad étnica, de las señas particulares de jefes, cargos, especialidades al interior del grupo. El tocado y toda la gama de textiles transmite una gran cantidad de información social: de género, etaria, laboral y otras que se nos escapan.

\section{Códigos del khipu}

Hablamos de códigos, en plural, al referirnos a los khipu, pues muestran, más que un código, un sistema de códigos que interactúan simultáneamente. En este sistema, un elemento afecta a todos los que lo componen. ¿Cómo representaban estos códigos la identidad étnica? Pärsinen y Kiviharju (2004) ofrecen una posible respuesta citando a Calancha: "Cada pueblo cabeza de provincia tenía su cifra" (2004:45). Esta información, realmente valiosa, no ha sido interpretada correctamente: la palabra "cifra" no ha sido "leída" sincrónicamente sino diacrónicamente. Pärsinen y Kiviharju indican que "han mencionado que cada provincia y cada capital de provincia tenía su propio número" (2004:51) en el khipu, que se representaría por un nudo o un conjunto de nudos. Covarrubias ([16011] 1995:310), bastante cercano al momento de la escritura de Calancha, nos dice qué significaba "cifra": "1. Escritura enigmática, con caracteres peregrinos, o los nuestros trocados unos por otros, en valor o en lugar. Cifrar. Recopilar una cosa y reducirla a pocas razones. 2. Descifrar, declarar algunas palabras oscuras". Queda claro que "cifra" en los siglos XVI y XVII no está relacionada con números sino con formas de comunicación poco claras o desconocidas. Se refiere a producir un mensaje encriptado o cifrado ${ }^{6}$. Calancha, con el término "cifra", no se refería a un número, sino a una forma extraña u oscura (para los occidentales) de expresarse. Descartamos que el khipu contenga "números" que representen topónimos y, más bien, tendría información étnica encriptada en su estructura, probablemente en la cuerda principal, que vendría a ser algo así como el llautu o la vincha del khipu, la sección preeminente.

Radicati también utiliza la palabra "cifra" para describir las características de la codificación del khipu: “... en las escrituras ideográficas ... en que los ideogramas se manifiestan en forma de cifras que se distinguen también por su color" (1984:378). La referencia a la palabra es ambigua. Si en esta cita "cifra" significa "código", está utilizando correctamente la acepción antigua; si significa "número", la moderna. Pero, la alusión a los ideogramas enlaza la discusión de los khipu con los caracteres chinos. Los ideogramas son formas expresivas que representan ideas figurativamente, no son signos que grafican la cadena fónica de la lengua (Burns 1981; Fernández y Gargurevich 2001). Los khipu, y cada una de sus cuerdas, anudadas o no, representan conceptos y 
no palabras, sílabas, letras ni grafías de una lengua específica. Tampoco grafican ideas. Es decir, utilizan un sistema semasiográfico (Urton 2017:16) o semasiológico, en donde el signo conlleva una carga semántica que conduce al concepto. Sus unidades mínimas (nudos, cuerdas) representan conceptos de variada complejidad. Una vez que se establezcan estas unidades mínimas de significado, se puede abordar el tema de su combinación.

La cuerda principal es el semema ${ }^{7}$ mayor: rige a las colgantes que serían sememas menores (Fossa 2011). Estos sememas estarían formados por las tramas de hebras de colores que configuran cada cuerda, siendo la transversal la más compleja, la que contiene información más rica; y por la seriación de colores en las colgantes (Conklin 2002:66) y (Chirinos 2010). La confección misma de la cuerda lleva carga significativa: el material, la torsión, el grosor, el/los colores ${ }^{8}$, la ubicación, el anclaje, la relación con las cuerdas contiguas, la presencia y direccionalidad de subsidiarias, y algún otro aspecto que no hemos identificado aún (Fossa 2011).

Cada grupo étnico registraría la codificación de las cuerdas, utilizando sus propias características formales y cromáticas. Por eso, aunque todas las comunidades hacían khipu, los de una no podían leer los khipu de la otra: cada provincia o nación tenía su khipu cifrado de acuerdo con los patrones de su propio arte textil. Escribe Calancha: “... para denotar las provincias de donde eran pondrían torzales de diferentes colores, en que se significava tales y tales provincias porque cada una tenía misturas diferentes..." (1639: 91). Porras comenta esta cita: "Los colores..., los torzales o hilillos mezclados indicaban con sus combinaciones características, como los clanes escoceses, las diferentes provincias del imperio" (1951: 46).

De la Vega también hace esta diferenciación textil: “... porque cada provincia tiene sus cuentas y nudos con sus historias anales y la tradición de ellas y por esto retiene mejor lo que en ella pasó que lo que pasó en la ajena" ([1609]1995:49). Este autor asistió a la escuela de nobles indígenas y de mestizos, hijos de españoles y mujeres "nobles" en el Cuzco. Allí tenía como condiscípulos a representantes de diversos grupos étnicos, poseedores de sendos "archivos" de khipu que contenían las relaciones de sus hechos históricos. Indica que tienen más memoria de la propia historia que de la ajena, pues a nivel provincial sus khipu solo registran la propia.
Recordemos lo que opina Ondegardo, confirmando la versión de Garcilaso: “... y aunque en el registro de los incas muy por extenso hallamos memoria, tambien cada provincia tiene sus registros ... de su tierra..." (1990:42).

La matemática Marcia Ascher nos ofrece conclusiones importantes de sus hallazgos:

\begin{abstract}
"En un khipu... los nudos... constituyen la información que se coloca en las cuerdas dispuestas de una manera específica. La estructura lógica de la configuración de las cuerdas es el marco de referencia para la interpretación de la información. Esto es, ambas, la estructura y los datos que allí aparecen, tienen carga informativa. Cada configuración se define por la forma en que están colocadas las cuerdas, su espaciamiento y sus colores. ... Son estas características y sus interrelaciones las que definen la estructura lógica de una disposición -determinan el formato en el que se coloca la información específica" (2002: 90) $)^{9}$.
\end{abstract}

Según Ascher, la información no solo está en el color de las cuerdas, sino en la forma en que ese color se ha presentado en ellas, privativo de cada grupo étnico. Hay por lo menos cuatro patrones de color presentes en las colgantes: jaspeado o moteado, helicoidal, por sectores y con añadidos de hilos de colores o marcadores (Pereyra 2006). Calancha ya nos había advertido sobre esto:

“... eran unos ilos de diversos colores de lana: unos eran de un color solo, otros de dos, otros de tres, i otros de más, porque los colores sinples i las mezcladas todas tenían sus significaciones por sí... Por los colores sacavan lo que se contenía en aquel tal ilo..." (1639:90).

Esta cita es clave para reconocer la injerencia del cromatismo en la carga semántica que alberga el código del khipu.

Los conceptos de "estructura" y de "configuración" que utiliza Marcia Ascher adquieren gran importancia. Efectivamente, ella define configuración del khipu como "la forma en que están colocadas las cuerdas, su espaciamiento y sus colores". Ascher se refiere aquí a las colgantes, que siempre penden 
de una principal, la base tanto de la organización física de las colgantes como de la organización del sentido: es el elemento que elimina la ambigüedad. En cuanto a la "estructura", sigue la lógica que regula la organización del sentido que cada grupo étnico le da a los contenidos que expresa. Ascher ha formulado estos conceptos luego de observar cuidadosamente más de doscientos ejemplares de khipu. No ha observado el estilo sencillamente porque no lo estaba buscando: su objetivo era contribuir a desentrañar el significado de los khipu estudiando los nudos, sus formas, sus posiciones y sus combinaciones.

Prada (1995:20) describe la organización Charca basado en un documento del Archivo General de Indias e indica que

“... los indios tributarios podían ser agrupados semánticamente tejiendo en la parte superior [del khipu] los colores característicos del vestido de la etnia, en este caso los charcas, para notar gráficamente a quién pertenecía el censo que el khipu contabilizaba".

La "parte superior" es, pues, la cuerda principal, confirmando que esta contenía una gran cantidad de información.

Brokaw cita a Prada en su artículo del 2003, y apoya el planteamiento de ese autor con palabras de Cieza: “... yvan [personas fieles y de confianza del Inca] de pueblo en pueblo mirando el traje de los naturales..." (1985:50-51). Como en la cita de Ondegardo no se trata solamente de mirar superficialmente, sino de verificar que el cromatismo esté de acuerdo con lo previsto para esa etnia particular. Según Brokaw, Cieza sugiere que "el Inka podría haber impuesto características específicas a la vestimenta étnica [regional] para facilitar el registro en khipu; hubiera sido relativamente fácil codificar esa información en khipu" $(2003: 135)^{10}$. Asimismo, el Inka reparte obsequios entre los grupos étnicos que van a "hazerle reverencia", en aceptación de su predominio, $\mathrm{y}$, en reciprocidad, viste la ropa de esos grupos, confirmando, metafóricamente, su individualidad al interior del Tawantinsuyu. La cita dice:

“... a los quales [Yauyos, de Tarama y otros muchos] reçibio bien dandoles a unos mugeres y a otros coca y a otros mantas y camisetas y poniendose el traje que tenia la provincia donde él estava, que fue por donde ellos reçibian mas contento" (Cieza 1985:162).

Se entiende, entonces, que las "mantas y camisetas", regalos del inka, probablemente ropa de cumbi o de arte plumario, podrían ser considerados hoy como una condecoración o un título honorífico, mientras que respeta y singulariza la indumentaria local al vestir como ellos.

Prada afirma la identidad entre el cromatismo textil propio a cada una de las distintas etnias con los khipu que esa misma etnia producía:

"Esta observación de Cieza ... insinúa la observación meticulosa de las diferencias de la vestimenta de las diversas etnias con fines administrativos que estaban ligados a la posterior anotación de los tributos por medio de khipus... se pudo realizar anotando gráficamente cada etnia según las características de su traje. Es decir, cada cuerda del khipu podía haber llevado la señal distintiva del traje de la etnia o ayllu respectivo, posibilitando así una diferencia precisa..." (1995:28).

Prada no habla acá de la cuerda principal, que llevaría la mayor carga semántica, sino de las colgantes que ostentarían también los patrones de colores específicos del grupo étnico, sus seriaciones, sus repeticiones, coincidiendo, en principio, con mi propuesta.

Según Juan de Betanzos ([1551] 1987:56), una de las primeras tareas de Ynga Yupanque cuando inicia su reconstrucción del Cuzco fue que: "le trujesen por cuenta cada uno dellos los indios que allí consigo tenían e luego los señores caciques le trujeron por quipo que dice cuenta la suma de los indios que tenían...". Como Ynga Yupangue va a repartir las tareas de construcción, necesita saber con cuánto personal cuenta. Esa información se la brindan los señores "que eran a él sujetos", cada uno a partir de sus propios "quipos". Esta cita señala, no solo la antigüedad de los khipu, sino la diferenciación étnica de los khipu. El inka no pide que le traigan sus khipu inka para que sus propios khipukamayuq los lean; les pide a los señores étnicos que traigan los suyos y los lean delante de él. Las particularidades de cada grupo étnico alcanzan a 
sus modos de registro, especialmente a sus khipu. Luego, cuando llega el momento en que el Ynga tiene que asignar los tributos entre los señores provinciales, se repite la situación:

“... el Ynga les mandó que le dijesen qué tenían en sus tierras y qué posibilidad alcanzaba cada uno y que le dijesen la verdad porque él tenía ordenado de poner en cada provincia de cada uno dellos un orejón señor natural de los del Cuzco a quien ellos y cada uno dellos respetase en su tierra como a su persona el cual sabría lo que ansí cada uno tenía e poseía e como él supiese que le había dicho mentira cualquier dellos que entendiese que había de morir por ello e luego los caciques mandaron traer allí los quipos memorias que ellos tienen y ansí mesmo por pinturas lo que ansí tenían e poseían y del arte y suerte que era la tierra e provincia de cada uno dellos..." (Betanzos ([1551] 1987:96).

Los jefes étnicos le llevan al Inka khipu y pinturas para darle la información in situ. Se necesita de esos khipukamayuq locales para decodificar la información de sus khipu que ni el Inka ni sus propios khipukamayuq pueden recuperar. Se trata de información producida por los grupos étnicos, señoríos locales o "provincias". Una vez que se ha cumplido con esta tarea, ya el inka está en capacidad de imponer los tributos "mandando hacer destos quipos e memorias dos, uno que llevase el tal cacique [jefe étnico provincial] e otro que quedase en poder de aquellos señores [del inka]" (Betanzos ([1551] 1987:97). Se observa aquí que, por una parte, había copia de khipu para diferentes instancias de poder y responsabilidad y, también, la información que viene del jefe étnico y sus khipukamayuq se transfiere al inka quien manda hacer los khipu a sus propios khipukamayuq. Estos los comparten con los jefes étnicos, en un proceso de ascenso y descenso de la información por la estructura jerárquica imperante. Se observa que el khipu es la herramienta indispensable para la gestión del Tawantinsuyu (Urton 2017: 5). Desde esta perspectiva se aclara la expresión de Cobo "...ni entre los mismos quipocamayos entendían los unos los registros y memoriales de los otros..." (en Pärsinen y Kiviharju 2004: 33). Sucede que los khipukamayuq de un grupo étnico, aunque saben codificar y decodificar khipu, tienen un código de color, de seriación, de combinatorias que no comparten con otros grupos étnicos.

Altieri resalta la habilidad que muestran algunos investigadores modernos para distinguir, "a simple vista, un kipu desenterrado en Ica, de otro de Cajamarquilla" (1990:87). Confirma así que un buen observador identifica un khipu de un grupo étnico específico, y lo puede asociar a una cultura que ocupa un espacio determinado, aunque sea disperso, como en un archipiélago de zonas geográficas.

\section{Diversificación vertical de los khipu}

Andrés Chirinos (2010) ha comparado khipu arqueológicos con transcripciones documentales de khipu de diversos grupos étnicos. En su trabajo se aprecia la relación entre territorio, población prehispánica y, al interior de ella, el tipo de khipu que utilizaba cada nivel organizativo para sus diferentes actividades. Lo destacable es la organización vertical, los niveles que la componen, el tipo de funcionario que le corresponde a cada una y, por consiguiente, el tipo de khipu (local-étnico o inka general) que lo acompaña. Este trabajo nos ayuda a visualizar la lógica de la funcionalidad de los diversos khipu, cada uno correspondiente a un uso administrativo: mantenimiento de almacenes, censos poblacionales, turnos de trabajo comunitario, reproducción ganadera. El licenciado Francisco Falcón hizo lo propio en 1567. Su Representación es la fuente de la Tabla 2.

Robert Ascher refuerza la argumentación precedente: “... el registro en khipu se adapta a muchos sistemas diferentes de significado, y para cada sistema se genera un khipu o un conjunto de khipu diferente" (2002:106) ${ }^{11}$. Deducimos que el contenido rige la estructura del khipu. Además, cada estructura adquiere el estilo propio del grupo étnico, determinado por el uso del color y la organización de las cuerdas.

Martha Ascher nos lo advirtió: "Para reconocer un formato es necesario que las estructuras lógicas correspondan con el conocimiento de la cultura" $(2002: 94)^{12}$. Y añade:

“... el asunto es que, para relacionar un khipu con un significado en el mundo inka, uno debe primero reconocer y establecer sus estructuras lógicas individuales. Cada 
Tabla 2. Organización administrativa Yunga e Inka (Falcón 1946 [ca 1567]:134-138). Probables tipos de khipu utilizados*.

\begin{tabular}{|c|c|c|c|}
\hline $\begin{array}{l}\text { Categoría territorial / } \\
\text { poblacional }\end{array}$ & Funcionario & Categoría colonial / Función & Tipo Khipu \\
\hline Tawantinsuyu & Inka & Inka & Capac \\
\hline Cuatro Suyu & Apocuna & Gobernador & Capac \\
\hline \multirow[t]{3}{*}{ Juez, señor de 10000} & Hunu & Señor & Capac \\
\hline & Tukuy rikuq & Visitador & Capac \\
\hline & Michuq & Teniente del Tukuy rikuq & Capac \\
\hline 5000 & Pichka waranqa kuraka & cacique & Local, censos, administración \\
\hline 1000 & Waranqa Kuraka & cacique & Local, censos, administración \\
\hline 500 & Pichka Pachaka Kuraka & cacique & Local, censos, administración \\
\hline 100 & Pachaca Kuraka & cacique & Local, censos, administración \\
\hline 50 & Pichca Chunka Kuraka & cacique & Local, censos, administración \\
\hline 10 & Chunka kuraka & cacique & Local, censos, administración \\
\hline Provincial & & $\begin{array}{l}\text { Principal provincial de pastores: } \\
\text { crianza y reproducción }\end{array}$ & Capac/Laboral \\
\hline Local & Hatun ${ }^{16}$ curaca & $\begin{array}{l}\text { Señores, mandones / Conteo } \\
\text { y distribución de ganado }\end{array}$ & Laboral \\
\hline Local & Curacas & Caçiques, mandones & Laboral \\
\hline Local & Runa & $\begin{array}{l}\text { Indios comunes / Guarda } \\
\text { del ganado }\end{array}$ & Laboral \\
\hline Provincial & Capac hocha camayuq & $\begin{array}{c}\text { Responsable de llevar los } \\
\text { sacrificios a donde se le mandaba }\end{array}$ & Capac/Laboral \\
\hline Provincial & Cori Camayuq & Responsable de labradores minas & Capac/Laboral \\
\hline Provincial & Llacxa camayuq & $\begin{array}{c}\text { Encargado de quienes labran } \\
\text { piedras marinas, turquesas y } \\
\text { otras }\end{array}$ & Capac/Laboral \\
\hline Provincial & Ichma camayuq & $\begin{array}{l}\text { Encargado de quienes labraban } \\
\text { tierras de colores }\end{array}$ & Capac/Laboral \\
\hline Local & Guaca camayuq & Encargado de cuidar las guacas & Laboral \\
\hline Local & Llano paucar camayuq & $\begin{array}{l}\text { Encargado de obtener plumas } \\
\text { finas }\end{array}$ & Laboral \\
\hline Local & Hawa paucar camayuq & $\begin{array}{c}\text { Encargado de obtener plumas } \\
\text { corrientes }\end{array}$ & Laboral \\
\hline Local & Llano pachac cumpic camayuq & $\begin{array}{l}\text { Supervisor factura ropa fina para } \\
\text { el Inka }\end{array}$ & Laboral \\
\hline Local & Hawa cumpic camayuq & Supervisor factura ropa basta & Laboral \\
\hline Local & Tanti camayuq & $\begin{array}{c}\text { Supervisor factura colores } \\
\text { vegetales }\end{array}$ & Laboral \\
\hline Local & Llano Hojota camayuq & $\begin{array}{l}\text { Supervisor factura sandalias finas } \\
\text { para el Inka }\end{array}$ & Laboral \\
\hline Local & Hawa Hojota camayuq & $\begin{array}{c}\text { Supervisor factura sandalias } \\
\text { bastas }\end{array}$ & Laboral \\
\hline Local & Tocllay Llica camayuq & $\begin{array}{l}\text { Supervisor guardas de las } \\
\text { mujeres para servicios del sol }\end{array}$ & Laboral \\
\hline Local & Intip Guarmin camayuq & $\begin{array}{l}\text { Supervisor guardas de las } \\
\text { mujeres para servicios del sol }\end{array}$ & Laboral \\
\hline Local & Mamacona camayuq & $\begin{array}{c}\text { Encargado de velar por las } \\
\text { mujeres mayores }\end{array}$ & Laboral \\
\hline Local & Aclla camayuq & $\begin{array}{l}\text { Encargado de velar por las } \\
\text { mujeres jóvenes }\end{array}$ & Laboral \\
\hline
\end{tabular}

*Listado parcial.

Fuente: Elaboración propia. 
estructura es particular a alguna situación. Uno debe trabajar a partir del conocimiento de la cultura para reconstruir lo que esta situación podría ser" (Ascher 2002: 99) ${ }^{13}$.

Al parecer, todos los khipu que ha estudiado Ascher pertenecen al "mundo inka". Al interior de este mundo encuentra diferentes estructuras que corresponden a situaciones determinadas. Podemos ver estas diferencias estructurales de otra manera: cada tipo de estructura pertenece a una etnia diferente, en su interior existen khipu que se utilizaron para expresar diferentes situaciones, como se observa en la Tabla 2.

El inka es un nivel de comunicación superior, al que llegaban todas las líneas de comunicación que partían de las etnias. Bajo este nivel tendríamos otros, regionales, locales, que, además de estar estructurados bajo su propia lógica, tienen marcas y señales identitarias. Se ha identificado khipu wanka (administración de almacenes) (Cieza, Brokaw, Chirinos), khipu charka (distribución de cargas laborales) (Ondegardo, Prada, Chirinos), khipu wari (Radicati), khipu chacha (encontrados en la cueva de los Cóndores, contexto funerario), khipu pachacamac (Bueno, Pereyra), khipu warku (encontrados en Incahuasi, Cañete, por Alejandro Chu, contexto administrativo ${ }^{14}$. Algunos se han estudiado contrastándolos con documentos coloniales; otros se han descrito en contexto. En algunos casos se le ha dado más énfasis al contenido; en otros se ha priorizado la estructura y el formato. Se ha llegado a establecer que ciertas características formales son wari (khipu entorchados) y otros inka, por su complejidad de expresión y su densidad de contenido.

Alberto Bueno hace una oposición entre los khipu polícromos grandes y los de Pachacamac (que él encontró) y que "considera (de) un nivel de contabilidad local y valor documental restringido" (1990:104). El contraste se daría con los "polícromos de extensión múltiple, en los que se consignarían mayores datos y valores a nivel macroestatal" (1990:104). Bueno asocia los polícromos grandes con un nivel "multisuyos" (inka), general, y los menos elaborados con un "suyo" (Pachacamac) local. Señala una relación vertical entre los khipu generales, regionales y locales.

Con la descripción de khipu de probada procedencia de Pachacamac (Pereyra 2006), de Puruchuco, de Chachapoyas, tendríamos ejemplares característicos de niveles intermedios o regionales, más que generales. Una observación importante en el caso de Pachacamac es que reunía múltiples grupos humanos diversos en un solo espacio, mitmaq o peregrinos, cuyos estilos y características diferían. Revisando los especímenes, las fotografías y las descripciones de las cuerdas transversales o principales y las colgantes se puede observar que existen estilos distintos que pertenecerían a grupos étnicos determinados. Aunque no es fácil, se hace necesario asociarlos estilísticamente a la producción textil propia de su grupo étnico.

\section{Conclusiones}

El arte textil andino expresa contenidos significativos mediante los colores, diseños y formas de su vestimenta y adorno. No hay dudas de que el llautu era identitario; no debería haberlas en cuanto al khipu que, aunque no es una prenda de vestir, es un textil, de algodón o de lana de camélido, que expresa significados por medio de su estructura, su combinación de colores y la disposición de ellos en la cuerda principal, entre otros aspectos.

El asociar la cuerda principal, las colgantes y los marcadores del khipu con el llautu por tratarse de objetos textiles, contribuye a avanzar la investigación a partir de lo que ya se conoce, asociándole ideas nuevas que pueden resultar muy productivas para reunir especímenes de acuerdo con estilísticas étnicas diferenciadas. Cada khipu estructurado corresponde a una situación al interior de la cultura del grupo étnico determinado que tiene las características esenciales y diferenciadoras en todas sus prendas textiles.

Por todo lo anterior, considero que tanto el khipu como el llautu formarían parte de una misma familia de textiles de acuerdo con sus rasgos cromáticos y de diseño; ambos objetos serían "textos" informativos, discursos, que reúnen las condiciones para establecer su capacidad identitaria. 


\section{Referencias Citadas}

Acosta, Josef de

(1590) 2008 Historia natural y moral de las Indias. Edición crítica de Fermín del Pino-Díaz, CSIC, Madrid.

Altieri, A.R.

1990 "El kipu peruano". En Quipu y Yupana. Colección de escritos. Ed. Carol Mackey et al, CONCYTEC, Lima, 77-87.

Anónimo (Blas Valera)

1951 [1586] Vocabulario y phrasis de la lengua general de los indios del Perú, llamada quichua y en la lengua española, Ed. Fac. Instituto de Historia, UNMSM, Lima.

Ascher, $\mathrm{M}$.

2002 "Reading Khipu: Labels, Structure, and Format". En Narrative Threads. Accounting and Recounting in Andean Khipu, J. Quilter y G. Urton, Eds., pp. 87-102. UTexas Press, Austin.

Ascher, R.

2002 "Inka Writing". En Narrative Threads. Accounting and Recounting in Andean Khipu, J. Quilter y G. Urton, Eds., pp. 103-115. University of Texas Press, Austin.

Bertonio, L.

1879 [1612] Vocabulario de la lengua Aymara. Teubner, Leipzig.

Betanzos, J.

1987 [1551] Suma y narración de los Incas, MC. Martín, Ed., Atlas, Madrid.

Brokaw, G.

2003 "The Poetics of Khipu Historiography: Felipe Guaman Poma de Ayala's Nueva corónica and the Relación de los quipucamayos". Latin American Research Review, Vol. 38, $\mathrm{N}^{\mathrm{o}} 3: 111-147$.

Bueno, A.

1990 "Hallazgo de khipu en Pachacamac". En Quipu y yupana. Colección de escritos. Ed. Carol Mackey et al., pp. 97-104. CONCYTEC, Lima.

Burns, W.

1981 "La escritura de los incas". En Boletín de Lima, $\mathrm{N}^{\mathrm{os}}$ 12-14, pp. 1-15.

Calancha, A.

1639 Coronica moralizada del Orden de San Augustin en el Perú con sucesos egenplares vistos en esta monarquía. Barcelona.

Chirinos, A.

2010 Quipus del Tahuantinsuyo. Curacas, incas y su saber matemático en el siglo XVI. AECID y Editorial Commentarios, Lima.

Chu, A.

Incahuasi, Cañete. Comunicación personal: mayo-junio 2014.

Cieza de León, $\mathrm{P}$.

1985 [ca 1551] Crónica del Perú. Segunda Parte, El señorío de los Yngas. Segunda edición, Prolg y Notas F. Cantù. Fondo Editorial Pontificia Universidad Católica del Perú, Lima.

Cerrón Palomino, Rodolfo

2016 "El lenguaje como hermenéutica en la comprensión del pasado: a propósito del puquina en la génesis del imperio incaico", en Diálogo Andino No 49, 11-27.

Conklin, W.

2002 "A Khipu Information String Theory”. En Narrative Threads. Accounting and Recounting in Andean Khipu. Ed. J. Quilter y G. Urton, pp. 53-86. UTexas Press, Austin.
Covarrubias, $\mathrm{S}$

1995 [1611] Tesoro de la lengua castellana y española, Ed. Castalia, Madrid.

De la Vega, G.

1995 [1609] Comentarios reales de los Incas. Ed., Carlos Araníbar, FCE, México.

Hernández Astete, Francisco

2016 "Leer el pasado andino en los textos coloniales" en Diálogo Andino $\mathrm{N}^{\circ}$ 49, 29-36.

Falcón, F.

1946 [ca 1567] "Representación hecha por el Licenciado Falcón en Concilio Provincial sobre los daños y molestias que se hacen a los indios" en Los pequeños grandes libros de historia americana. Serie I, Tomo X, Lima. pp. 123-172

Fernández, M. y T. Gargurevich

2001 Escritura Incaica, Editorial de la Universidad Nacional Federico Villarreal, Lima.

Fossa, L.

2011 https://www.academia.edu/35061538/ Khipu_y_discurso_Paralelismos_en_el_mundo_andino

2006 Narrativas problemáticas. Los Inkas bajo la pluma española, Instituto de Estudios Peruanos, Fondo Editorial de la Pontificia Universidad Católica del Perú y Author's Fund de la Universidad de Arizona, Lima.

González, D.

1989 [1608] Vocabulario de la lengua Qquichua o del Ynga. UNMSM, Lima.

Greimas, A.J. y J. Courtès

1982 Semiótica. Diccionario razonado del lenguaje. Versión española de H. Campodónico y E. Ballón, Ed. Gredos, Madrid.

Guaman Poma, F.

1993 [ca 1615] Nueva coronica y buen gobierno, Edición F. Pease G.Y. FCE, Lima.

Levillier, Roberto

1925 Gobernantes del Perú. Cartas y papeles. Siglo XVI. Documentos del Archivo de Indias, Prólogo Horacio Urteaga, Tomo IX El virrey Martín Enríquez 1581-1583, Imprenta de Juan Pueyo, Madrid.

Ondegardo, $\mathrm{P}$.

1990 [1571] Notables daños de no guardar a los yndios sus fueros... (El mundo de los incas) L. González y A. Alonso, editoras. Historia 16, Madrid.

Pachacuti Yamqui, J.

1993 [1613] Relacion de antiguedades desde reino del Perú, Comentario etnohistórico: P. Duviols. Comentario lingüístico: C. Itier. Ed. IFEA y CBC, Cusco.

Pärssinen, M. y J. Kiviharju

2004 Textos andinos. Corpus de textos khipu incaicos y coloniales, Tomo I. Instituto Iberoamericano de Finlandia y Universidad Complutense de Madrid, Madrid.

Pereyra, $\mathrm{H}$.

2006 Descripción de los quipus del Museo de sitio de Pachacamac. Proyecto Quipu. CONCYTEC, Lima.

Perissat, K.

2000 "Los Incas representados (Lima-siglo XVIII): ¿supervivencia o renacimiento?”. En Revista de Indias, vol. LX, núm. 220. pp. 623-649

Pizarro, $\mathrm{P}$.

1986 Relación del descubrimiento y conquista de los reinos del Perú. Edición, G. Lohmann. PUCP, Lima. 
Porras, R.

1951 "Quipu y quilca. (Contribución histórica al estudio de la escritura en el antiguo Perú)". En Revista del Museo e Instituto Arqueológico, pp. 19-53. Universidad Nacional Cuzco, N ${ }^{\text {os. }} 13-14$, Cuzco.

Prada, F.

1995 "El khipu incaico: de la matemática a la historia". En Yachay. Revista de cultura, filosofía y teología, pp. 11-37. Año 12, No 21, UCB, Cochabamba.

Radicati, C.

1984 "El secreto de la quilca". En Revista de Indias, pp. 11-62. XLIV (Nº 173), Madrid.
1990 "Hacia una tipificación de los quipus" en Quipu y yupana. Colección de escritos. Ed. Carol Mackey et al., CONCYTEC. Lima. 89-95.

Diccionario de la lengua española. http://www.rae.es/RAE/ Noticias.nsf/Home?ReadForm (26 junio 2011).

Sarmiento, P.

1988 [1572] Historia General Llamada Indica. Miraguano Editores y Editorial Polifemo, Madrid.

Urton, G.

2017 Inka History in Knots. Reading Khipus as Primary Sources. University of Texas Press, Austin.

\section{Notas}

1 El uso de la frase "textos textiles" quiere resaltar el uso antiguo de la palabra texto, que emerge del antiguo arte textil. Asimismo, destacar la asociación de la palabra textil con su valor discursivo.

2 "Son quipos unos memoriales o registros hechos de ramales, en que diversos ñudos y diversos colores significan diversas cosas. Es increíble lo que en este modo alcanzaron, porque cuanto los libros pueden decir de historias y leyes y ceremonias y cuentas de negocios todo eso suplen los quipos tan puntualmente que admira... Porque para diversos géneros... había diversos quipos o ramales, y en cada manojo déstos tantos ñudos y ñudicos e hilillos atados - unos colorados, otros verdes, otros azules, otros blancos- y finalmente tantas diferencias que, así como nosotros de veinte y cuatro letras -guisándolas en diferentes maneras- sacamos tanta infinidad de vocablos, qsí éstos de sus ñudos y colores sacaban innumerables significaciones de cosas" (Acosta (1590) 2008:210).

3 Si consideramos el khipu como discurso, estamos asumiendo que es un objeto codificado que registra y transmite información a quien conozca el o los códigos. Muchos historiadores, como Hernández Astete (2016:29-30), continúan centrándose en la escritura alfabética para clasificar a los grupos humanos como susceptibles de que su historia pueda ser escrita: “¿Cómo escribir respecto de los incas desde la historia si carecemos de escritura, pues hasta ahora nadie puede leer ninguno de los soportes que aparentan serlo, y es necesario hacer este proceso únicamente con textos coloniales y con evidencias materiales?". Prefiero la pregunta: ¿Cómo podemos desentrañar los códigos del khipu y de los textiles andinos en general para conocer mejor el pasado? Para una discusión más amplia del interesante tema, véase Fossa 2006.

$4 \quad$ Llautu es un cíngulo largo que dan muchas vueltas, que se ponen los del Cuzco en la cabeza y cada nación se diferencia por lo que traen en la cabeza (Anónimo [1586] 1951:54).

5 Vincha: guirnalda de indias que traen en la cabeza (Anónimo [1586] 1951:87).

6 "cifra. 3. f. Escritura en que se usan signos, guarismos o letras convencionales, y que solo puede comprenderse conociendo la clave..." (DLE 2011).

7 "Semema.... el conjunto de semas (unidades mínimas semánticas) que puede ser reconocido dentro del signo... [esto conforma] la unidad de significación..." (Greimas y Courtès 1979:358).

8 "En el corpus de los khipu... hay un khipu que contiene tres tipos diferentes de uso del color. Uno es una cuerda de color utilizada especialmente para separar grupos; otra eran hilos de diferentes colores insertados en una porción de las colgantes, y el tercero era usar un color en una parte de la colgante y luego empalmarlo con otro color". Mi traducción de: In the khipu corpus... there is a khipu containing three different types of color usages. One usage was a specially colored cord to separate groups; another was different colors threaded through a short portion of the pendants, and the third was using one color part way down a pendant and then, by splicing, continuing with another color (Ascher, M. 2002:95).

9 Mi traducción de: On a khipu ... knots ... are the data that are placed into the cord array. The logical structure of the cord array is the framework for the interpretation of the data. That is, both the structure and the data within it, carry information. Each array is defined by how the cords are placed, how they are spaced, and by their colors. ... It is these features and their interrelationships that define the logical structure of an array -they shape the format into which the specific data are placed (2002:90).

10 Mi traducción de: The Inka may have imposed specific features of ethnic dress in order to facilitate khipu record keeping, and it would have been fairly easy to encode such information on a khipu (Brokaw 2003:135).

11 Mi traducción de: ... khipu writing is adaptable to many different systems of meaning, and for each such system a different khipu or set of khipu comes into being" (2002:106)

12 Mi traducción de: To recognize a format requires matching cultural knowledge with logical structures (Ascher, M. 2002:94).

13 Mi traducción de: ... the point is that to relate a khipu to meaning in the Inka world, one must first recognize and establish their individual logical structures. Each structure is particular to some situation. One must work from knowledge of the culture to reconstruct what the situation might be (Ascher, M. 2002:99).

14 En la década de 1980, Radicati no estaba de acuerdo con esta "regionalización" de los khipu (1990:91), quizás debido a una insuficiente cantidad de ejemplares descritos en su tiempo. 
15 Epíteto de uso privativo para referirse a los incas. Término de procedencia puquina-colla (Cerrón 2016: 15).

16 Según Cerrón (2016:21) se ha confundido hathu_sustantivo aimara, con $h a t u(n)$, adjetivo quechua. En el presente caso se está utilizando hatun, según la definición de González Holguín: a "lo mayor, o mejor, o superior más principal o más conocido" (1952;I:154 [1608]), Hatun kuraka sería un superior de los kuraka. 